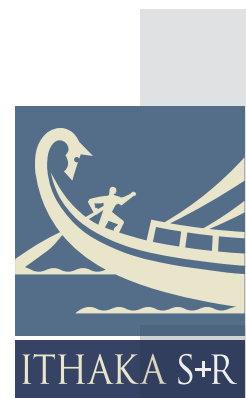

Ithaka S+R Case Study

\title{
American Antiquarian Society
}

Worcester, Massachusetts

www.americanantiquarian.org

The Ithaka S+R Case Studies in Sustainability were conducted in partnership with the Association of Research Libraries and were made possible by the generous support of the Institute of Museum and Library Services. A summary report, "Searching for Sustainability: Strategies from Eight Digitized Special Collections," is available at http://www.sr.ithaka. org/research-publications/searching-sustainability. This specific case study was researched and written by Deanna Marcum, Managing Director, Ithaka S+R.

\section{ABSTRACT}

The American Antiquarian Society (AAS), an independent research library and scholarly society, has a clearly defined mission: to collect everything published and printed in America prior to 1877. The AAS has traditionally operated from a small endowment and contributions. But what began as an effort, in 1955, to convert print to microform turned into a source of income when in 2002 Readex, a publisher of digitized historical primary source materials, began to reissue AAS-based products in digital form, paying the Society royalties that quickly grew to be a significant revenue stream. By 2006, this experience had encouraged the president of the AAS and its Council to cultivate a portfolio of commercial partners that would help digitize the collection, thus contributing to the AAS's transition to a new digital environment, while also paying royalties. Those royalties now total close to $\$ 1.1$ million annually from the commercial partners' sales to other libraries of these digital collections. This case study does not focus on a single digitized collection, but examines the strategy of an institution with a welldefined scope and its determination to supplement its budget with royalties derived from licensing agreements with a variety of partners.

\section{INTRODUCTION}

The American Antiquarian Society, located in Worcester, Massachusetts, is an independent not-for-profit

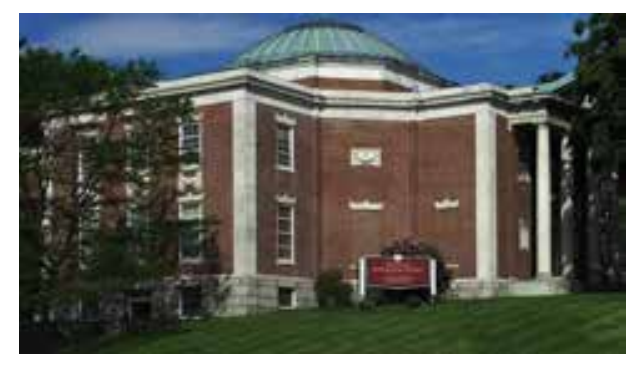

The American Antiquarian Society, Worcester, Massachusetts. Courtesy of the American Antiquarian Society. organization with a well-defined mission: to collect, preserve, and make available for study all printed records of what is now known as the United States of America, from the time of the first European settlement through the year 1876. In 2002 AAS began working with a commercial partner, Readex, to reissue in digital form items from their collection that they had started to microfilm nearly half a century earlier. In 2006 the current president of AAS, Ellen S. Dunlap, expanded that effort to a roster of additional publishers with an eye to having the entire AAS collection digitized, largely at the publishers' expense. AAS deliberately sought out a 
variety of partners, each with different business models and markets, for the same reason that an investor seeks diversity in a stock portfolio: to expand revenue opportunity and concurrently reduce business risk. This would serve AAS not only by helping it adapt to the digital environment and allowing it to collect royalties from its commercial partners, but also by providing AAS with scans that could be made freely available at the end of the commercial publishing effort.

In the course of its two hundred years of existence, AAS has collected approximately three million items-a tremendous resource for researchers and, now, other libraries. The collections are made up of books, pamphlets, newspapers, periodicals, graphic arts, ephemera, and manuscripts. The Society has collected two-thirds of all known books printed in the United States before 1820, and it has the largest and most comprehensive collection of American newspapers printed before 1876. For the time period it covers, the American Antiquarian Society is a national repository.

The Society is well known for its service to its users. Scholars who have been in residence at the AAS are asked to complete a survey at the end of their visits, and in it many of them indicate that the services provided by the AAS staff are unparalleled. The AAS offers programs for scholars, precollegiate, undergraduate, and graduate students, educators, professional artists, writers, genealogists, and the general public. In order to bring new researchers to its collections, the Society provides approximately fifty funded fellowships for research in the collections from four weeks to twelve months, and it has an educational program that offers research and study opportunities for graduate students, teachers, journalists, and creative writers and artists.

The Vigilantes of Montana, or Popular Justice in the Rocky Mountains. Courtesy of the The American Antiquarian Society has a staff of fifty-two and an elected Council made up of scholars from the fields of early American history and literature along with collectors, public historians, and community and business leaders. The Council and AAS leadership recognized early in the era of digitization that publishers were interested in their content; they also understood that, by forming partnerships with publishers of all types, they stood to gain the financial means to fund and expand the overall mission of the organization and develop the resources needed to maintain its physical assets, fund its programs and fellowships for researchers, and retain expert staff to manage the digitization processes.

\section{BACKGROUND}

The story of how the AAS came to digitize its collection begins more than fifty years before the first page was scanned. Mindful of the need to make its collections more readily accessible to the scholarly community, the AAS began a program of microfilming its collections in 1955, and even in those early years made the

Seeking commercial partners would allow them to digitize the collections while also generating ongoing financial support in the form of royalties determination that to fulfill the goal of providing access to a wider community, it would need a commercial partner that had the capacity for filming large collections and marketing the microform copies to the academic library community. Through its partnership with the publisher Readex (which later

became a division of NewsBank), AAS led the successful effort to make all known pre-1820 American imprints and newspapers available in microform, thus permitting the study of early American history on campuses far removed from the East Coast libraries where most of the extant copies were to be found. 
In 2006, the organization established a deliberate digital strategy that included two key elements: it would attempt over time to systematically digitize everything on its shelves, avoiding the kind of rogue digitizing that creates a "virtual pile of stuff," in the words of AAS President Ellen Dunlap. She worried that the haphazard kind of digitization that was taking place could put at risk the preeminence AAS had achieved as a well-defined, comprehensive collection. To capitalize on that preeminence in the digital age, Dunlap believed that AAS would need to move aggressively on multiple fronts, and engaging multiple partners seemed to be the most promising strategy for moving quickly. Yet, as had been the case back in the 1950s, there were questions about the Society's capacity to undertake such a large-scale systematic effort, and AAS considered how it might undertake digitization at scale. Seeking to find a way to fund ongoing digitization, she used the situation as an opportunity to think creatively.

AAS determined that its collections had value, and the administration and Council concluded that seeking commercial partners would allow them to digitize the collections while also generating ongoing financial support in the form of royalties. In the absence of institutional funding such as a university library would enjoy, or an endowment large enough to sustain the organization, this royalty income would help support the full range of activities of the organization. The Council saw merit in the plan, even though a few Councilors-most notably some of the academics - expressed regret that the Society was not in a position to digitize its collections without the "pay wall" limitations that commercial partnerships entail. But fiscal realities ultimately helped everyone to fully embrace the notion that, while some

The organization nets approximately $\$ 1$ million that it then uses to invest in capital projects, collection development, and strategic initiatives to keep the AAS vibrant institutions are raising money to digitize collections so that they can provide free access to them, AAS has adopted a strategy of making its past investments in collections work for the future of the institution and ultimately to the benefit of all. The Council approved

the general plan, leaving the details of individual contracts to Ellen Dunlap. Once that key decision was made, however, it was "all in," according to Dunlap, and the organization set about determining how best to execute the plan. To develop the program, Dunlap sought advice from a digital strategy and business consultant, and from that early discussion, a partnership was formed between AAS and Hal Espo, President of Contextual Connections, LLC, who helped develop AAS's digital strategy and has served the Society as consultant and commercial agent since 2006. His role has been to help make the introductions to key publishers and to serve as an agent, negotiating the terms for each contract. With his help, in 2006 AAS set up a competition among publishers for access to its highly specialized content and, by 2008, a half-dozen deals were in the works.

\section{SUSTAINABILITY STRATEGY}

The Society generates its support—about \$5 million in 2012 —in a several ways: \$1 million comes through grants and donations to the Society, $\$ 2.5$ million stems from an endowment, and $\$ 1.5$ million is generated through "auxiliary activities", most of the latter sum is from the royalties the private partnerships provide. After expenses attributed to operating its licensing program, the organization nets approximately $\$ 1$ million that it then uses to invest in capital projects, collection development, and strategic initiatives to keep the AAS vibrant. This section will focus just on the licensing activity.

\section{Economic Model}

One advantage the AAS has is that its collection is well defined; it is very large, comprehensive by nature, and bounded by geography and time. The AAS librarians had many ideas about the materials likely to be of interest to other libraries, though it is important to note that while they are insightful about the materials and how they are used in the scholarly community, like most library and curatorial staff elsewhere, the AAS staff had no 
substantive experience in the greater commercial marketplace. As pleased as AAS was that Readex was moving from microfilm to digitization, it was eager at the same time to pursue other digitization opportunities with publishers whose experience in various markets would both complement and supplement the interests and experience of Readex.

AAS has two considerations for the partnerships it enters into: to ensure that the digital content becomes available to AAS to use in any way it wishes after some agreed-upon period of time, and to earn as much money through the licensing agreements as possible. In forming the partnerships, the Society recognized that the marketplace is not monolithic, and thus its strategies and contract terms vary according to the publisher. In the words of the president, "AAS is not setting the demand; it is meeting the demand." Publishers are expected to provide information about user needs from their market research, and then the librarians work with them to determine the scope of the content to be digitized. The library set out to create as many of these agreements as possible. Financial targets were not set by AAS as a strategy, but it has learned through each opportunity what value its content has in each market. The primary initial goal was to determine whether the Society could form partnerships that would allow it to digitize its collections.

The Society had to account for a new way of doing business. The expenses that AAS has had to cover with this new approach include the agent's fees; the salary of a staff member who serves as an expediter for the digital projects, and a full-time second person in her unit; the set-up costs for the scanning area; and the additional electrical and data network capacity that was needed for infrastructure. All of these hard costs are tracked separately and provided to the Council in regular financial reports. AAS does not track soft costs-Dunlap's time and the curators' time are treated as part of their regular jobs. The costs of the two dedicated staff, the agent, legal fees, travel, and miscellaneous expenses have averaged $\$ 140,000$ per year. Revenues from licensing agreements have averaged \$1.2 million per year, and since the early days of its partnerships, AAS has recognized that there would be an additional need to project the revenue income and plan for much-needed capital improvements based on when the large payments would be coming in. Over the years, AAS has gained expertise in tracking expectations, and it projects the revenue it will receive each year.

The royalty streams will not last forever, so the Council wants to use the funds to make capital improvements or to purchase large collections that would be otherwise impossible for the library to acquire. All of the contracts with publishers are of limited duration, and recognizing this reality, the AAS has established a list of priorities for using the revenues generated from licenses.

\section{Partnerships}

Dunlap wanted to secure partners who would agree to a long-term and substantive relationship with AAS, though she appreciated that there are always multiple means to an end, and thus not all of AAS's commercial relationships are alike or even as she might have hoped. Throughout, as steward of the materials themselves, AAS wanted its commercial-facing activity to enlighten the organization about end-user needs, and Dunlap realized that, on virtually all issues, the expertise of AAS and that of the publishers are different and complementary. Dunlap cited data mining, digital humanities trends, and discovery as examples of emerging areas in which the publishers have added significantly to the understanding of AAS staff. The publishers, in turn, have learned a great deal from the staff about collections and their value to scholarship. Needless to say, this kind of relationship between a cultural heritage organization and publishers is not common. As the parties have gained experience with their partnership, each has learned from the other, to their mutual benefit. 


\section{How AAS structures its partnerships}

When AAS decided to pursue commercial licensing partnerships, it had some experience, having already worked with a publisher in the microfilm era, and it had a huge corpus under license because of the microform agreements. The Society did not see it as a big step to extend commercial partnerships in the digital era.

The terms of each contract vary, but the Society insists upon a number of features:

- AAS aims to maximize the revenue it generates through its licensing agreements with commercial partners. Throughout the term of any commercial license, the publisher must pay royalties to AAS.

- AAS actively seeks long-term licenses, extending from five to twelve years, with precise provisions that allow for extensions, terminations, and other key factors.

- AAS owns the scans, and at the end of the term of the contract AAS must have unfettered use of them.

- Many of AAS's contractual agreements include a provision that specifies the revenue targets that must be met.

- The scans created must be of sufficient quality to represent AAS well, though they need not be "preservation quality," which demands a level of effort generally unsupported by commercial activity.

The AAS librarians and curators are enthusiastic about the partnerships they have nurtured with the publishers. One of the essential requirements set out in the license agreements is that the two parties stay in touch with each other throughout the projects. AAS staff are often consulted by the publishers for their bibliographical knowledge, and they always have the last word when it comes to how the collection materials can be safely handled during the scanning process. Publishers often turn to AAS for names of scholars familiar with the collections to serve as advisors for their projects, and they seek advice from staff as they develop research tools and interface features for the digital products. AAS staff see the positive impact of extended collection reach and of their own activities in support of the use which comes from that extended reach.

AAS considers its licensing program to have been an unqualified success. Dunlap's metric is very simple: she measures success not by clicks or Google analytics, but by the size of the checks she receives, and by the number of publishing partners who return to do more work with AAS.

\section{Public Benefit}

While the immediate benefits of the private partnerships are financial, AAS believes that there are substantial long-term public benefits to this approach as well. As of 2013, AAS licensing agreements have yielded 25 million scans, and eventually all of that digital content will come back to AAS as digital files that can be made publicly available at the conclusion of the commercial publishing effort.

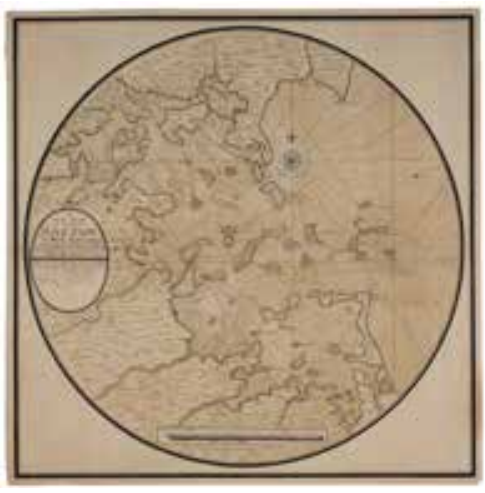

A New Plan of the Harbour of Boston in New England. Courtesy of the American Antiquarian Society.
In the meanwhile, there have been other, more immediate public benefits of this work. As a result of the coordinated digital workflow, all items that are digitized, even by partners, are cataloged by AAS and therefore discoverable through the AAS's main digital catalog. To facilitate access to the online products, whenever it is feasible AAS builds links between its own OPAC records and digitized items that are currently in a commercial partner's collection; for researchers affiliated with institutions that have purchased access to that collection, the links will provide direct access to the desired items. Also, AAS has used licensing revenue in many ways that benefit the public, most importantly by the investment of more than $\$ 1$ million in acquisitions that add to the strengths of AAS collections. It has been able in many cases to acquire collections - which it could not have afforded out of its regular collection-development budget - that would otherwise have been dispersed 
to private collectors. And it has been able to expand efforts at cataloging certain collections that have for too long been "hidden" at AAS. Moreover, AAS has facilitated access to collections by the creation of online tools such as Clarence (which provides issue-level cataloging for its vast newspaper collection) and MyWebAAS (which eases the process of requesting materials in the reading room and ordering reproductions online).

Revenue from commercial partnerships has also made it possible for AAS to digitize important portions of its collection that it chooses to make freely available via a digital asset management tool called GIGI (which stands for Graphical Interface of Gathered Images, but is really an homage to Curator Emerita Gigi Barnhill). Rich with metadata and linked to individual OPAC records, GIGI currently contains about 80,000 scans created by the AAS staff photographer as a result of collection projects (some grant funded), patron orders, and staff requests. The number of items in GIGI is growing at a prodigious rate, and it affords the scholarly community and the general public alike a window into the AAS collections, especially those manuscript and graphic arts collections that are outside the purview of the current publishing partners.

\section{KEY FACTORS OF SUSTAINABILITY}

1. An integrated digital workflow. The key to success for AAS is that the digitization it has undertaken is not a separate activity or a bolt-on operation. When the decision was made to digitize the entire collection, the president of AAS recognized that the entire staff had to embrace the digital environment. There is not a separate workflow for digitized collections. There is a single workflow, and digital work is spread throughout the organization. Everyone has a role, and every one of the commercial partnerships is managed by a library professional.

Perhaps because of strong leadership, perhaps because of their already strong service ethic, or perhaps because they see digital as the future, staff members appear to be supportive and enthusiastic about the direction of the library. In all of our interviews, there was not a hint that anyone sees digital as a threat. In fact, there was unusual excitement about the digital future on the part of a staff that has long tenure with the organization.

2. Bringing in external expertise to create a new, and different, program. The AAS hired someone with industry expertise to build a focused approach to the commercial world and ultimately negotiate on its behalf. The library knew it had to learn quickly how to operate in its chosen commercial markets, and bringing in someone with that expertise gave it needed insight into how publishers think and what they would need from a partnership, as well as what AAS could fairly expect and how best to achieve its objectives.

The library understood that it was not expert in negotiating contracts and concluded that for this strategy to be successful, it had to identify an agent who possessed relevant business and negotiating skills. The president of AAS turned to someone she knew to be a consultant to publishers and asked if he would accept a consulting assignment with a library. He agreed.

At first, Hal Espo worked as a strategy consultant to the library, and in a short time his role was expanded to include that of agent. His fees as an agent are a function of concluded contracts and revenue generation. If the library and a given vendor/publisher cannot come to an agreement, Espo receives no related compensation. His role is multifaceted: he has become deeply familiar with the AAS collections, and he routinely "pitches" ideas to publishers for digital projects; he negotiates terms of the agreements; he brings with his work an experienced intellectual property attorney to develop lengthy (up to fifty pages) and comprehensive agreements that protect the interests of the library; he works hard to maintain AAS relationships with 
publishers; and he keeps the AAS Council informed about AAS's licensing business and the markets in which the Society commercializes its content. In the beginning of the consulting assignment, he coached the AAS president on becoming more business-savvy. The president is very pleased with the result, and Espo takes great pride in the business acumen that the president has developed over time.

\section{ONGOING SUSTAINABILITY ISSUES}

- Community unease with a model that does not offer wide access. Some in the research library community have expressed concern that this strategy, while successful for AAS in terms of generating funding, does not offer enough public benefit, since the commercial partners have tended to use the content in fee-based products only. Dunlap's response to this concern has been that AAS does not have a provost to appeal to for money in next year's budget; the strategy is a good one for "an institution that has to pay its own light bill." She points out that AAS has for two centuries acted as a steward for these collections in the interest of the public good, and that private support is now needed to keep these materials accessible - on site at present, and online in the future. Moreover, she is able to point to all of the mission-related strategic investments - from acquisitions, to cataloging, to capital improvements of all sorts— that have been possible only because of this new revenue stream.

- Less direct contact with scholars. The commercial partnerships pose a philosophical dilemma: While people are using its collections with much greater frequency, the collections are no longer deeply connected to AAS. The library prides itself on the relationship it enjoys with the scholars who come to use its collections, and yet it has little say in how the content is made accessible to those who use it online. Dunlap worries that this could undermine the deep connections AAS staff have enjoyed with their users. The library recognizes that it will have to be much more engaged in the digital humanities if it is to meet scholars where they are working, and to that end has just announced the appointment, under the ACLS Public Fellows program, of a full-time digital humanities curator.

- Long-range strategy for sharing the digitized content. The next challenge is to design a strategy for what to do, ultimately, with those scans that are being created by all the partners. The current infrastructure of AAS is not capacious enough to ingest and make accessible the large number of digital files. The AAS is thinking seriously about how to work with other organizations to make the digital files available in the future. Dunlap believes that market forces and the academy are building infrastructures that will accommodate these scans.

\section{LESSONS FOR OTHERS}

1. Unique content may be valuable to the right publisher. AAS has a collection that is both wide and deep, and other libraries may have a harder time creating similar arrangements. On the other hand, many organizations have deep, albeit smaller specialities, and may be able to use a similar strategy for commercializing those collections. Other institutions will have to choose the right business style for themselves: Will they focus on the best of, or all of, a particular collection?

2. Understanding how to measure this value is critical. When AAS chose to work with private partners, it understood that these partners were planning to create products that would ideally be profitable, and it took steps-including bringing in someone with experience in this domain — to negotiate on its behalf. Determining licensing terms, including royalty fees, exclusivity clauses, and other contractual terms that will have an impact on financial and public benefit, should be done with a deep and nuanced understanding of the marketplace. 
3. Developing a strategy to fit your mission is essential. While there has been criticism from some quarters about the AAS digitization strategy, Dunlap sees this effort as a necessary means to move the AAS and its significant cultural assets securely into the future. Her mandate includes stewardship of not just the virtual collection but the physical collection and the landmark building that houses it, and the decision to prioritize commercial partnerships serves this stewardship. Project leaders and institutional directors will need to carefully assess the aims and mission of their initiatives, as well as the range of resources available to them, when crafting a mission-aligned strategy. 
APPENDIX

Interviewees

Ellen S. Dunlap, President, American Antiquarian Society

Hal Espo, President, Contextual Connections, LLC, consultant and agent for the AAS

Susan Forgit, AAS Finance Director

AAS Content Coordinators

Lauren Hewes, Andrew W. Mellon Curator of Graphic Arts

Tom Knoles, Marcus A. McCorison Librarian and Curator of Manuscripts

Marie Lamoureux, Collections Manager

Elizabeth Watts Pope, Curator of Books

Laura Wasowicz, Curator of Children's Literature

S. J. Wolfe, Senior Cataloger and Serials Specialist

AAS Technical Staff

Meg Bocian, Digital Expediting Coordinator

Nick Conti, Director of Information Technology

Alan Degutis, Head of Cataloging Services

Babette Gehnrich, Chief Conservator

Christine Graham-Ward, Cataloger, Visual Materials

Kathleen Haley, Systems Librarian

Jackie Penny, Imaging Rights Coordinator

Resources Consulted

American Antiquarian Society Annual Reports, 2009-10, 2010-11, 2011-12, http://www. americanantiquarian.org/annualreports.htm.

"The American Antiquarian Society: Needs and Opportunities for a Third Century," unpublished paper used as background for AAS symposium "Research Libraries in in the Digital Age: Needs and Opportunities" on January 13-14, 2012.

This project was made possible in part by the Institute of Museum and Library Services, LG-06-10-0189-10.

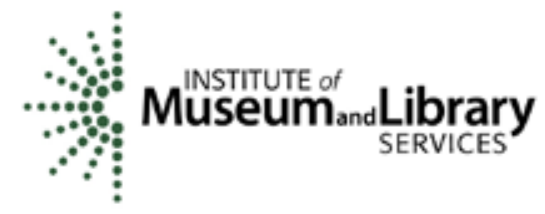

Copyright 2013 Association of Research Libraries. This work is licensed under a Creative Commons Attribution-Non Commercial-ShareAlike 3.0 United States License. To view a copy of the license, please see http://creativecommons.org/licenses/by-nc-sa/3.0/us/. 